\title{
Data-driven recognition memory: A new technique and some data on age differences
}

\author{
ALAN J. PARKIN \\ University of Sussex, Brighton, England \\ JAMIE WARD \\ University College London, London, England \\ and \\ ELLA J. SQUIRES, HELEN FURBEAR, ALICE CLARK and JULIA TOWNSHEND \\ University of Sussex, Brighton, England
}

\begin{abstract}
In this study, we investigate the effect on recognition memory of having target and distractor stimuli consisting of different combinations of low-level elements (letters), relative to when targets and distractors consist of combinations of the same elements (nonoverlap and overlap conditions, respectively). It was found that recognition memory was enhanced in the nonoverlap condition, even though subjects reported being unaware of this experimental manipulation. This confirms the importance of perceptually driven processing in the implicit memory component of recognition memory. The extent to which this effect occurs is found to be age dependent, with elderly subjects benefiting more from having targets and distractors consisting of nonoverlapping elements. This is consistent with the notion that elderly subjects show less reliance on item-specific/contextual detail to support recognition memory.
\end{abstract}

Ever since Mandler's (1980) seminal review paper, there has been research into the idea that recognition is a multiple-component process. Mandler argued that recognition comprised two components-recollection and familiarity. These terms were defined experientially as recognition associated with an accompanying context and recognition not associated with contextualinformation (see also Atkinson \& Juola, 1973).

One influential idea is that these two putative components of recognition can be distinguished in terms of conceptually driven and data-driven forms of processing (e.g., Blaxton, 1989; Gardiner, 1988; Jacoby \& Dallas, 1981). This idea was formalized in an experiment by Johnston, Dark, and Jacoby (1985). In the first part of this experiment, subjects were required to read some individually presented words. In the next phase these old words were presented along with an equal number of new words. At first, these words were severely degraded, but they gradually became clearer until a point was reached where subjects could name them. Following naming, subjects also had to indicate whether each word was old or new. The independent variable of interest was the speed of naming as a function of whether the words were old or new and

We are very grateful to Henry Roediger and Fergus Craik for helpful comments made on an earlier draft. This work was supported by a Human Frontiers Research grant and is dedicated to the memory of Alan Parkin. Correspondence concerning this article should be addressed to J. Ward, Department of Psychology, University College London, Gower Street, London WC1E 6BT, England (e-mail: jamie.ward@ucl.ac.uk). whether the recognition decision was correct. It was found that naming speed for old words was faster irrespective of whether the recognition response was correct.

Johnston et al. (1985) described this faster reading of old words as perceptualfluency; the idea was that a recognition response could be cued because perception of a previously seen item was easier, relative to an unseen control condition. Central to the idea of fluency is that context-free information regarding recognition emanates entirely from how the stimulus interacts with the perceptual system. This idea has been used extensively in the line of recognition research that has arisen from use of the process dissociation procedure (PDP). Briefly, Jacoby and his colleagues devised a paradigm in which subjects studied two different lists (e.g. Jacoby, 1991, 1998; Jacoby, Begg, \& Toth, 1997; Yonelinas, Regehr, \& Jacoby, 1995). In the exclusion condition, subjects were asked only to identify words presented in one list, whereas in the inclusion condition, they responded to any word they remembered seeing in the entire presentation phase. By examining the extent to which subjects falsely identified words from the excluded list, the PDP yielded two measures, termed recollection and familiarity, respectively. On the basis of previous work, such as that of Johnston et al., it was proposed that the familiarity component represented recognition that was driven by fluency-based information.

The PDP framework has had a considerable impact on memory research, but it has not been without its critics (e.g., Curran \& Hintzman, 1995; Dodson \& Johnson, 1996; Graf \& Komatsu, 1994; Komatsu, Graf, \& Uttl, 1995; 
Wagner, Gabrieli, \& Verfaellie, 1997). One important assumption has been that the recollection and familiarity components of recognition are independent. The debate surrounding this issue is somewhat complex and beyond the scope of this communication (but see Russo, Cullis, $\&$ Parkin, 1998). However, it would be fair to say that the interpretation of PDP data is more complex than once thought. Moreover, in relation to the fluency issue, although there is good evidence that tests of implicit memory such as repetition priming are perceptually based (e.g. Berry, Banbury, \& Henry, 1997; Roediger \& Srinivas, 1993), there has been very little direct evidence that perceptual fluency lies at the heart of the familiarity/automatic component of recognition memory.

An alternative to this approach has been provided by what has been termed the recognition and conscious awareness (RCA) paradigm, first devised by Tulving (1985). In this task, subjects first make a recognition response and are then asked to decide whether they "remember" (i.e., recollect) a specific previous experience of the item or simply "know" that it is "familiar"- that is, that they have seen it somewhere before. Furthermore, it has been suggested that "know" judgments are based upon perceptual fluency (Gardiner, 1988). Work using this paradigm has produced a large amount of data showing that these subjective classifications of recognition memory react differently to a range of manipulations (Gardiner, 1988; Gardiner \& Parkin, 1990; Rajaram, 1993; for reviews, see Gardiner \& Java, 1993; Rajaram \& Roediger, 1997). However, as with PDP, evidence that familiarity responses are perceptually mediated is equivocal. For instance, changes in modality or image size between study and test are not captured by differences in "know" responding (Challis et al., 1993; Rajaram, 1993, 1996), even though it is well established that these manipulations influence perceptual memory, as has been shown by priming studies (e.g., Berry et al., 1997).

\section{Aims of the Present Study}

The present study was motivated by the need to try and provide some objective means of demonstrating whether recognition can be driven by the perceptual characteristics of stimuli. A further aim was to examine whether any influence of this kind reflected implicit or explicit aspects of memory performance. In the PDP literature, there is a working hypothesis that familiarity components of recognition consist of those components that are the output of implicit memory processes. Accounts of the RCA task and its findings are less clear in relation to the implicit/ explicit criterion. However, the assumption that "know" responses are more perceptually driven (e.g. Gardiner, 1988 ) is certainly compatible with an implicit contribution to recognition.

In the Johnston et al. (1985) experiment, fluency was defined at the word level, but there is no a priori reason to suppose that fluency could not operate at the subword level. Indeed, if fluency is the output of implicit memory processes, there is direct evidence to suggest that the memory mechanisms operate at the sublexical level (e.g., Hay- man \& Tulving, 1984). In the present experiment, we examine recognition performance in conditions that either maximize or minimize the availability of perceptual cues during recognition. In the minimal or nonoverlap (NO) condition, the target list comprises words derived from one subset of the alphabet, and the distractor items consist of words derived from the other half of the alphabet; thus, in this condition, targets and distractors do not share any letters. In the overlap $(\mathrm{O})$ condition, targets and distractors are derived from the entire alphabet. The logic of this experiment is that the presence of perceptual processing during recognition should cause a relative disadvantage in the $\mathrm{O}$ condition, because both targets and distractors will initiate letter-based fluency cues. In the NO condition, however, recognition should be eased, because the extent of fluency information from the distractors is reduced extensively. The degree to which this reflects implicit or explicit influences will be assessed by using subjects' test awareness - that is, whether or not they had any conscious awareness about the manipulation being undertaken in the experiment.

A third aspect of this study concerned a particular hypothesis about the nature of recognition memory as a function of normal aging. The literature on human aging and recognition presents a slightly confusing picture, but a general finding is that, with advancing age, recognition memory deteriorates principally because older subjects are more likely to produce false alarms, as opposed to lower hit rates (e.g., Bartlett, Strater, \& Fulton, 1991; Rankin \& Kausler, 1979; Reder, Wible, \& Martin, 1986; but see Light \& Anderson, 1983). One explanation of this is that older subjects are less reliant on contextual information in recognition judgments and so are more likely to accept the distractor items on the basis of their preexperimental familiarity. Parkin and Walter (1992) showed that "know" responses increased markedly with age and with an accompanying increase in false alarm rates. In the present study, we examine whether older subjects are more sensitive to perceptual similarity in recognition.

\section{EXPERIMENT 1}

\section{Method}

Subjects. The details of the subjects are summarized in Table 1. The young subjects were recruited through the Sussex University subject pool, and the elderly subjects were recruited primarily through a nonresidential day center. The elderly subjects were screened for dementia, using the Mini Mental State Examination (Folstein, Folstein, \& McHugh, 1975). The average score was $28.8(S D=1.15)$, and the range was 26-30, which was well above the cutoff of 24 . The groups were matched for estimated IQ, using the National Adult Reading Test (NART; Nelson, 1985). Subjects were offered $£ 5$ for participating.

Materials. The materials consisted of 200 words. In the NO condition, 50 words were selected that were composed entirely of 13 letters of the alphabet (a, e, y, b, d, g, j, l, n, r, t, w, z), and 50 words were selected composed entirely out of the remaining 13 letters (i, o, u, $\mathrm{c}, \mathrm{f}, \mathrm{h}, \mathrm{k}, \mathrm{m}, \mathrm{p}, \mathrm{q}, \mathrm{s}, \mathrm{v}, \mathrm{x})$. Words in the $\mathrm{O}$ condition $(N=100)$ were composed by using the full range of letters, with the constraint that each must contain at least 1 letter from the two pools of letters that had been used in the NO condition. This was done to maximize the 
Table 1

Details of Subjects (Experiment 1)

\begin{tabular}{lllllllrr}
\hline & & \multicolumn{3}{c}{ Age } & & \multicolumn{3}{c}{ NART-IQ } \\
\cline { 3 - 4 } \cline { 7 - 9 } Subjects & $N$ & Mean & $S D$ & Range & & Mean & $S D$ & Range \\
\hline Young & 28 & 21.1 & 1.8 & $19-25$ & & 113 & 4.1 & $105-122$ \\
Elderly & 28 & 74.0 & 6.1 & $60-89$ & & 119 & 10.4 & $106-127$ \\
\hline
\end{tabular}

difference between the stimuli in the two conditions. The words used in the $\mathrm{NO}$ and $\mathrm{O}$ conditions had mean frequencies of 59.0 ( $S D=$ 179.6) and $56.3(S D=192.9)$, respectively (Kučera \& Francis, 1967). The mean word lengths in the NO and O conditions were 4.70 $(S D=1.21)$ and $4.99(S D=1.53)$, respectively. Word imagery ratings were also obtained, on a 1-7 scale, from 15 other (young) subjects, using the instructions of Paivio, Yuille, and Madigan (1968). The words used in the NO and $\mathrm{O}$ conditions had mean imagery ratings of $4.40(S D=2.41)$ and $4.48(S D=2.30)$, respectively. None of these differences was significant.

Design. In the overlap condition, the stimuli were randomly divided into four lists of 25 words. In half of the subjects (14 young, 14 elderly), two lists were used as target stimuli, and the other two lists as distractor stimuli (Set A). The remaining subjects saw the same lists, but with the target/distractor roles reversed (Set B). Thus, each word appeared both as a target and as a distractor an equal number of times, counterbalancing between subjects. Stimuli in the NO condition were divided similarly, counterbalancing the target/ distractor status between subjects. The $\mathrm{O}$ and $\mathrm{NO}$ conditions were presented as a within-subjects factor, and the order of presentation of lists was rotated across subjects (O-NO-NO-O or NO-O-ONO). The lists can be found in the Appendix.

Procedure. The subjects were seated in front of an Apple Macintosh computer. They were informed that they would be shown a sequence of words on the computer screen, which they would be asked to recognize later on. In the study sequence, 25 items were displayed centrally for 2,000 msec, followed by a gap of $500 \mathrm{msec}$. There was a 4-min retention interval, during which time the subject was engaged in conversation. The recognition sequence consisted of the 25 targets and 25 distractor items in a random order. Each word was presented individually on the computer screen, and the subject was asked to make an oral "yes" or "no" judgment as to whether the word had been previously presented or not. This was self-paced. There was a 1-min interval between the recognition sequence and the second study sequence, during which time the experimenter prepared the next block. The whole experiment took under an hour. The subjects were debriefed at the end of the session and asked to report whether they had noticed any similarities or differences between the words that had been displayed.

\section{Results}

Table 2 shows the mean hit and false alarm rates for the two conditions. A series of $2 \times 2$ analyses of variance (ANOVAs) was performed, with age as a between-subjects factor (elderly vs. young) and target-distractor perceptual similarity as a within-subjects factor (overlap vs. nonoverlap). For the false alarm rates, there was a significant benefit for the $\mathrm{NO}$ condition relative to the $\mathrm{O}$ condition $[F(1,54)=27.42, p<.001]$ and a main effect of age, with the elderly producing more false alarms $[F(1,54)=4.17$, $p<.05]$. Most important, however, there was a significant interaction between age and $\mathrm{O} / \mathrm{NO}[F(1,54)=6.95, p<$ $.01]$ such that the elderly benefited more from having targets and distractors composed from nonoverlapping pools of letters. This supports the notion that reducing the overlap between perceptual cues in targets and distractors re- duces the probability of false recognition and that this effect is heightened with increasing age. The same overall trend was found for the hit rates, but in this instance, none of the effects reached or approached significance [age, $F(1,54)=.55$, n.s.; overlap, $F(1,54)=2.06$, n.s.; interaction, $F(1,54)=1.77$, n.s.].

Planned comparisons between young versus elderly (independent-samples $t$ tests) revealed only one significant result - namely, between false alarm rates in the $\mathrm{O}$ condition $[t(54)=2.56, p<.05]$. No other result approached significance. This is consistent with previous studies (e.g. Parkin \& Walter, 1992) showing that in "standard" recognition testing $(\mathrm{O})$, elderly subjects are prone to false recognition. However, minimizing the perceptual similarity of targets and distractors (NO) enables the elderly to perform at a level comparable with that for younger subjects.

Planned comparisons between $\mathrm{O}$ and NO (pairedsamples $t$ tests) revealed the following results. There were significantly fewer false alarms in the NO, relative to the $\mathrm{O}$ condition in both young $[t(27)=2.50, p<.05]$ and elderly $[t(27)=4.61, p<.001]$ subjects. There was a higher hit rate in the NO condition, relative to the $\mathrm{O}$ condition in elderly subjects $[t(27)=2.18, p<.05]$, but not in the younger ones $[t(27)=0.07]$.

Debriefing. The fact that the subjects were unaware of the manipulation was borne out by comments in the debriefing. None of the subjects reported noticing that seen words were sometimes composed of different letters from unseen words, and the subjects appeared surprised when the experimenter informed them of this fact. Also, there was no evidence from the subjects' reports that they had partial knowledge of the manipulation (e.g., the letter "A" was seen a lot), which might improve performance, but without leading to perfect performance. In Experiment 2, we investigated subjects' awareness of the manipulationfurther.

Signal detection analyses. The use of signal detection measures to interpret recognition memory data is contro-

Table 2

Hit and False Alarm Rates (Mean Percentages, With Standard Deviations) in the Overlap and Nonoverlap Conditions (Experiment 1)

\begin{tabular}{|c|c|c|c|c|}
\hline \multirow[b]{2}{*}{ Condition } & \multicolumn{2}{|c|}{ Elderly } & \multicolumn{2}{|c|}{ Young } \\
\hline & $M$ & $S D$ & $M$ & $S D$ \\
\hline \multicolumn{5}{|c|}{ Hit Rate } \\
\hline Overlap & 79.0 & 16.8 & 78.0 & 16.9 \\
\hline Nonoverlap & 83.0 & 13.7 & 78.2 & 14.1 \\
\hline \multicolumn{5}{|c|}{ False Alarm Rate } \\
\hline Overlap & 19.3 & 15.0 & 10.4 & 10.0 \\
\hline Nonoverlap & 11.0 & 11.3 & 7.7 & 9.6 \\
\hline
\end{tabular}


versial (see Clark \& Gronlund, 1996, for a review) and may be most suitable for models that assume that recognition is based on the strength of a single underlying measure, rather than for dual-process models. The measures are reported here primarily for completeness and to enable comparison with other studies.

Discriminability and bias measures were calculated for each condition, using measures based on the normal distribution (Stanislaw \& Todorov, 1999). ${ }^{1}$ The results are shown in Table 3 . Two separate $2 \times 2$ ANOVAs were performed on the discriminability and bias measures. The results suggest that the critical interaction between age and $\mathrm{O} / \mathrm{NO}$ is due to differences in discriminability $[F(1,54)=5.45, p<$ $.05]$, and not in bias $[F(1,54)=0.15$, n.s. $]$. There was a significant main effect of $\mathrm{O}$ versus $\mathrm{NO}$ in terms of both discriminability $[F(1,54)=19.04, p<.001]$ and bias $[F(1,54)=10.08, p<.005]$. There was no significant main effect of discriminability between old and young subjects $[F(1,54)=2.07$, n.s. $]$, but there was a significant difference in bias $[F(1,54)=4.44, p<.05]$. A greater tendency toward affirmative responding in the elderly could reflect more reliance on perceptual fluency, rather than a deliberate criterion shift.

\section{EXPERIMENT 2}

The aim of Experiment 2 was to replicate the results of Experiment 1 , using a different set of materials and subjects (age range, 45-60 years), and to extend the findings with a more sensitive measure of implicit knowledge of the NO letter set, since verbal reports may not always be the best measure of implicit knowledge (e.g., Dienes \& Berry, 1997). The procedure was essentially the same, except that after recognition memory testing in the NO condition, they were instructed that all the words that they had been asked to remember conformed to a rule (they were not told what it was). They were then given a forced-choice test consisting of two new words, one of which conformed to the rule (i.e., composed of the same set of letters as the NO targets) and one that did not (i.e., composed of the same set of letters as the NO distractors). The test is implicit in the sense that subjects are required to categorize, rather than to recognize, and all items are new (as in implicit grammar learning; Reber, 1967). The experimental hypothesis was that subjects would show above-chance

Table 3

Signal Detection Analyses of Performance in the Overlap and Nonoverlap Conditions (Experiment 1)

\begin{tabular}{lcccc}
\hline \multirow{2}{*}{ Condition } & \multicolumn{2}{c}{ Elderly } & & \multicolumn{2}{c}{ Young } \\
\cline { 2 - 3 } \cline { 4 - 5 } & $M$ & $S D$ & & $S D$ \\
\hline Overlap & 1.77 & 0.65 & 2.25 & 0.89 \\
Nonoverlap & 2.33 & 0.74 & 2.41 & 0.79 \\
& \multicolumn{5}{c}{ Discriminability $\left(d^{\prime}\right)$} \\
Overlap & 1.74 & 2.53 & 3.78 & 4.74 \\
Nonoverlap & 2.93 & 3.49 & 5.29 & 5.25 \\
\hline
\end{tabular}

performance on this task, even when unaware of the rule. We also wanted to determine how easy it was for subjects to learn the rule when they were alerted to its presence (i.e., does categorization improve over trials).

\section{Method}

Subjects. Thirty-two middle-aged subjects took part (mean age, 52.2 years, $S D=4.1$, range $=45-60$; mean NART IQ $=115, S D=$ 5). They were paid $£ 4$.

Materials. The materials consisted of 240 words that had not previously been used in Experiment 1 . In the NO condition, 40 words were selected, which were composed entirely from a set of 13 letters (a, b, d, h, j, l, n, p, q, s, u, v, y), and 40 words were composed from the complementary set of letters (c, e, f, g, i, k, m, o, r, t, w, x, z). The $\mathrm{O}$ condition consisted of 80 words, utilizing the full range of letters, but drawing at least one letter from each of the two pools used in the NO condition. The words used in the NO and $\mathrm{O}$ conditions did not differ in terms of word length, word frequency (Kučera \& Francis, 1967), or imagery ratings. In addition, a further set of 80 words was chosen for the forced-choice categorization phase. Forty words were composed from the same set of letters as the NO targets, and 40 from the same set as the NO distractors.

Design. As in Experiment 1, half of the words were used as targets, and half were used as distractors, with each word appearing as a target and a distractor an equal number of times, counterbalancing between subjects. The $\mathrm{O}$ and NO conditions were a within-subjects factor, but unlike in Experiment 1, the order of presentation of lists was rotated in the orders $\mathrm{O}-\mathrm{O}-\mathrm{NO}-\mathrm{NO}$ or NO-NO-O-O . This was because the forced-choice categorization phase was always administered after two consecutive runs of the NO condition.

Procedure. The procedure for the presentation of study and recognition sequences was identical to that used in Experiment 1. The procedure for the forced-choice categorization phase was as follows. After the second NO recognition sequence, the subjects were asked whether they had noticed any similarities or differences between the words that they had just seen. They were then told that all the words that they had been asked to remember in the last two sequences had, in fact, followed a rule, and again they were asked whether they knew what it was. They were then told that they would be shown two new words, only one of which would follow the rule, and they would be asked to guess which one it was. It was even emphasized that the rule did not relate to semantic categories (e.g., animal vs. object) and that they should make their decision on the basis of their initial feeling and should try not to work it out. The 40 pairs of words were then presented one at a time, and the test was self-paced. The word following the rule appeared on the left and right of the screen equally often. After all 40 trials, they were again asked whether they could verbalize the rule. Finally, they were told the rule in the debriefing.

\section{Results and Discussion}

Table 4 displays the mean hit and false alarm rates and the signal detection measures for the 32 subjects. For hit rates, there was a significant benefit of the NO condition relative to the $\mathrm{O}$ condition $[t(31)=2.39, p<.05]$. Similarly, false alarm rates were significantly less likely to occur in the $\mathrm{NO}$ condition than in the $\mathrm{O}$ condition $[t(31)=3.06, p<.005]$. Since the targets for some subjects were distractors for others, the result cannot be due to the fact that the materials differ in their propensity to yield a "yes" response. Signal detection analyses of the data revealed that the NO condition was associated both with better discriminability, $d^{\prime}[t(31)=3.75, p<.001]$, and with an increase in the bias term, $\beta[t(31)=2.86$, $p<.01]$. These results replicate Experiment 1 . 
Table 4

Recognition Memory (Hits and False Alarms, in Percentages) and Signal Detection Measures $\left(d^{\prime}\right.$ and $\beta$ ) for the Overlap and Nonoverlap Conditions (Experiment 2)

\begin{tabular}{|c|c|c|c|c|c|c|c|c|}
\hline \multirow[b]{3}{*}{ Condition } & \multicolumn{4}{|c|}{ False } & \multirow{2}{*}{\multicolumn{2}{|c|}{$d^{\prime}$}} & \multirow{2}{*}{\multicolumn{2}{|c|}{$\beta$}} \\
\hline & \multicolumn{2}{|c|}{ Hits } & \multicolumn{2}{|c|}{ Alarms } & & & & \\
\hline & $M$ & $S D$ & $M$ & $S D$ & $M$ & $S D$ & $M$ & $S D$ \\
\hline Overlap & 84.7 & 8.2 & 5.5 & 4.4 & 2.70 & 0.75 & 2.81 & $\overline{1.58}$ \\
\hline Nonoverlap & 88.6 & 8.3 & 2.7 & 3.5 & 3.25 & 0.77 & 5.24 & 4.62 \\
\hline
\end{tabular}

The results of the forced-choice categorization phase are shown in Figure 1. The average score of the subjects $(62.3 \% ; S D=8.3)$, collapsing across positions in the list, was significantly above chance [one-sample $t(31)=3.29$, $p<.005]$. The figure also shows that subjects are able to categorize at an above-chance level (50\%), even for the first few items in the test. Interestingly, there is no evidence to suggest that their ability to categorize improves during the test. A comparison of subjects' scores on the first half of the test, relative to the second half of the test, revealed no significant difference [paired $t(31)=0.23$, n.s.]. This implies that subjects base their categorization judgments on the knowledge acquired in the previous recognition memory test, and not from logical deduction of the rule after being alerted to its presence. As in the previous experiment, the subjects were unable to report the rule (even in vague terms; e.g., some letters tended to be repeated more) before or after the categorization phase.

In summary, Experiment 2 has found, with different stimuli and subjects, that middle-aged subjects also show a benefit from minimizing the perceptual cues between targets and distractors. Moreover, we have presented more direct evidence that the difference in performance between $\mathrm{O}$ and $\mathrm{NO}$ recognition memory tests is mediated by perceptual fluency. This is because subjects are able to perform above chance on a forced-choice categorization test, which does not require overt recollection of previous items (since all the stimuli are new).

\section{GENERAL DISCUSSION}

In this study, we investigated the effect of varying the perceptual relationship between targets and distractors in a recognition memory test, so that in one condition (NO) targets were composed of different letters than were the distractors, whereas in the control condition $(\mathrm{O})$ targets and distractors were composed of the same set of letters. It was found that recognition memory was better in the $\mathrm{NO}$ condition that in the $\mathrm{O}$ condition, although the extent of the difference was age dependent (the elderly showed the greatest difference). These results suggest that recognition memory can be driven by relatively low-level (sublexical, perceptual) characteristics of the stimuli and that, furthermore, this can occur implicitly. In this instance, it was not necessary to employ mathematical equations, and the assumptions that accompany them, to ascertain that the effect was implicit. The manipulation was implicit in the sense that none of the subjects was consciously aware of the relationship between targets and distractors, and hence the subjects could not be using this information as an overt strategy to guide recognition. The fact that the effect was strongest in the elderly is broadly consistent with multiple-component theories of recognition memory (e.g., Mandler, 1980) and suggests that the elderly become more reliant on data-driven forms of processing than on recollection of the study episode. The implications for theories of recognition memory and aging are discussed in more detail below.

Recognition memory and aging. It is widely accepted that aging is associated with poorer recall of information (e.g., Craik \& McDowd, 1987). However, the evidence in favor of a decline in recognition memory with

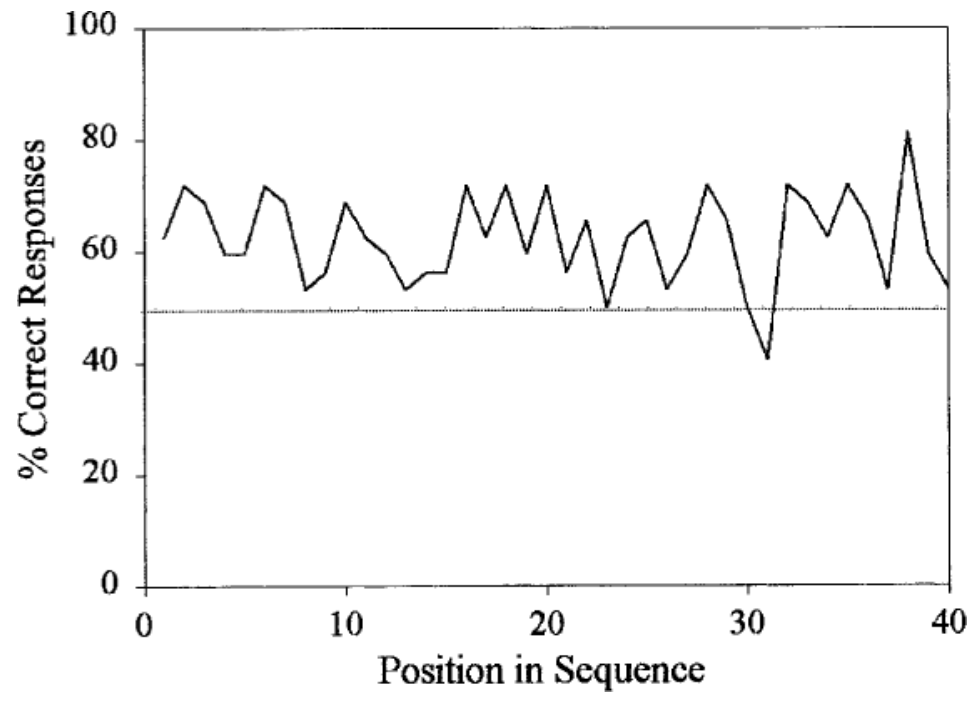

Figure 1. Forced-choice categorization of novel items which resemble the nonoverlap targets (Experiment 2). Chance is $50 \%$. 
age has proved to be more controversial (e.g. Craik \& McDowd, 1987; White \& Cunningham, 1982). One possible reason for this is that if one accepts that recognition memory is a multiple-component process, a deficiency in one aspect of recognition memory (i.e., recollection) may be compensated for by greater reliance on the other (i.e., familiarity/fluency). This may not necessarily manifest itself as a quantitative difference in performance, even though qualitative changes should be apparent (e.g., Parkin \& Walter, 1992).

In our experiment, there was a significant overall agerelated difference in recognition memory. Moreover, aging influenced the type of stimuli that were likely to be recognized. The elderly were significantly worse than the younger subjects in the $\mathrm{O}$ condition, but not in the NO condition (in terms of false alarms, but not of hits). This is consistent with the notion that aging produces a recognition memory impairment and that this impairment is characterized by greater reliance on the perceptual characteristics of stimuli, since a greater degree of perceptual overlap between targets and distractors had a particularly detrimental effect on recognition performance, relative to younger controls. This greater reliance on perceptual similarity may reflect a reduced ability to use item-specific or contextual detail in the elderly, which is also consistent with their difficulty on recall tests.

Our initial hypothesis was that perceptual similarity between targets and distractors appears to exert its effect predominantly on the false alarm rate. The memory description of the target stimuli consists of more generic characteristics of the stimuli (or gist) and lacks item-specific detail. In the NO condition, these generic characteristics could serve as a source of discrimination between targets and distractors (since distractors are composed of different letter elements). However, in the $\mathrm{O}$ condition, the distractors would tend to share many of the elements found in the memory description of the targets-leading to their false acceptance. ${ }^{2}$ Contrary to our original predictions, it now also appears that this manipulation may affect hit rates too (at least in elderly and middle-aged subjects). This could also be attributed to increased perceptual fluency in the NO condition. Having a smaller set of letters in this condition $(N=13)$ relative to the $\mathrm{O}$ condition $(N=26)$ means that the letters in the former will, on average, be repeated more and, hence, be more primed than in the latter.

Having considered the implications for theories of aging, we will now go on to discuss the wider implications for recognition memory.

Perceptually driven recognition memory. Although there is good evidence that certain implicit memory measures (e.g., priming) are related to the perceptual form of the presented items, evidence in favor of a perceptual contribution to recognition memory judgments has been more elusive. For instance, changes from study to test across modality (e.g., hear vs. see) and form (e.g., word vs. picture) affect perceptual priming but have little effect on recognition memory performance, even when recog- nition is partialled into recollective and familiarity components, using either PDP or RCA paradigms (e.g., Wagner et al., 1997). Other inconsistent results include the fact that although superior recognition of low-frequency words has been associated with increased perceptual fluency (Jacoby \& Dallas, 1981), low-frequency words are not associated with more "know" responses in the RCA paradigm (Gardiner \& Java, 1993), suggesting that the two mechanisms/measures cannot be equated.

Some more positive evidence for the role of implicit perceptual processes in recognition memory was, however, provided by Jacoby and Whitehouse (1989) and Rajaram (1993). They employed a repetition masking procedure in which test items were briefly presented as a mask immediately prior to being presented for a recognition judgment. The mask was presented too briefly $(50 \mathrm{msec})$ to be explicitly identified itself. In this condition, subjects were more prone to affirmative responding (higher hits and false alarms), consistent with the notion that an implicitly primed word form can lead to increased probability of recognition. This differs from the present experiment in that we have shown that perceptual distinctiveness can be protective against false recognition, particularly in the elderly (see also Schacter, Israel, \& Racine, 1999). This experiment also differs from the one by Jacoby and Whitehouse (1989) in that we have established that perceptually based recognition can be driven prior to the level of the word recognition system (see Tulving \& Schacter, 1990).

It is worthwhile to speculate why there has been so much inconsistency in the literature with regard to this issue. It is possible that the familiarity component estimated by PDP may be influenced by explicit retrieval under some circumstances (e.g., Russo et al., 1998), for instance, if subjects employ a generate-recognize strategy. As for the RCA paradigm, although this is intended to be a subjective measure of the subject's memory, the instructions given to the subject can often be theory laden. For instance, the instructions of Rajaram (1993) suggest that subjects should respond "remember" if they recollect something specific about the item's physical appearance. Thus, by definition, perceptual information can influence "remember" as well as "know" responding.

As we noted in the introduction, it is not the aim of this paper to present a critique of these existing approaches. The point that we wish to emphasize is that it is possible to establish different components of recognition memory by manipulating objective changes in stimulus characteristics, as opposed to making questionable assumptions about the relationship between recognition memory and processes, under either different task conditions or different forms of subjective classification.

\section{REFERENCES}

At Kinson, R. C., \& Juola, J. F. (1973). Factors influencing speed and accuracy of word recognition. In S. Kornblum (Ed.), Attention and performance IV (pp. 243-293). New York: Academic Press.

Bartlett, J. C., Strater, L., \& Fulton, A. (1991). False recency and false fame of faces in young adulthood and old age. Memory \& Cognition, 19, 177-188. 
Berry, D. C., Banbury, S., \& Henry, L. (1997). Transfer across form and modality in implicit and explicit memory. Quarterly Journal of Experimental Psychology, 50A, 1-24.

Blaxton, T. A. (1989). Investigating dissociations among memory measures: Support for a transfer appropriate processing framework. Journal of Experimental Psychology: Learning, Memory, \& Cognition, 15, 657-668.

Challis, B. H., Chiu, C.-Y., Kerr, S. A., Law, J., Schneider, L., Yonelinas, A., \& Tulving, E. (1993). Perceptual and conceptual cueing in implicit and explicit retrieval. Memory, 1, 127-151.

Clark, S. E., \& Gronlund, S. D. (1996). Global matching models of recognition memory: How the models match the data. Psychonomic Bulletin \& Review, 3, 37-60.

Craik, F. I. M., \& McDowd, J. M. (1987). Age differences in recall and recognition. Journal of Experimental Psychology: Learning, Memory, \& Cognition, 13, 474-479.

Curran, T., \& Hintzman, D. L. (1995). Violations of the independence assumption in process dissociation. Journal of Experimental Psychology: Learning, Memory, \& Cognition, 21, 531-547.

Dienes, Z, \& Berry, D. (1997). Implicit learning: Below the subjective threshold. Psychonomic Bulletin \& Review, 4, 3-23.

Dodson, C. S., \& Johnson, M. K. (1996). Some problems with the process-dissociation approach to memory. Journal of Experimental Psychology: General, 125, 181-194.

Folstein, M. F., Folstein, S. E., \& McHugh, P. R. (1975). Mini mental state. Journal of Psychiatric Research, 12, 189-198.

GARDINER, J. M. (1988). Functional aspects of recollective experience. Memory \& Cognition, 16, 309-313.

GARDINER, J. M., \& JAVA, R. I. (1993). Recognising and remembering. In A. F. Collins, S. E. Gathercole, M. A. Conway, \& P. E. Morris (Eds.), Theories of memory (pp. 163-188). Hove, U.K.: Erlbaum.

Gardiner, J. M., \& Parkin, A. J. (1990). Attention and recollective experience in recognition memory. Memory \& Cognition, 18, 579-583.

Graf, P., \& Komatsu, S. (1994). Process dissociation procedure: Handle with caution! European Journal of Cognitive Psychology, 6, 113-129.

Hayman, C. A. G., \& Tulving, E. (1984). Is priming based on a "traceless" memory system? Journal of Experimental Psychology: Learning, Memory, \& Cognition, 15, 941-952.

JACOBY, L. L. (1991). A process dissociation framework: Separating automatic from intentional uses of memory. Journal of Memory \& Language, 30, 513-541.

JACOBY, L. L. (1998). Invariance in automatic influences of memory: Toward a user's guide for the process-dissociation procedure. Journal of Experimental Psychology: Learning, Memory, \& Cognition, 24, 3-26.

JACOBy, L. L., BEgG, I. M., \& Tотн, J. P. (1997). In defence of functional independence: Violations of assumptions underlying the process-dissociation procedure? Journal of Experimental Psychology: Learning, Memory, \& Cognition, 23, 484-495.

JACOBY, L. L., \& DALlas, M. (1981). On the relationship between autobiographical memory and perceptual learning. Journal of Experimental Psychology: General, 3, 306-340.

JACOBY, L. L., \& Whitehouse, K. (1989). An illusion of memory: False recognition influenced by unconscious perception. Journal of Experimental Psychology: General, 118, 126-135.

Johnston, W. A., DARK, V. J., \& JACOBY, L. L. (1985). Perceptual fluency and recognition judgments. Journal of Experimental Psychology: Learning, Memory, \& Cognition, 11, 3-11.

Komatsu, S., Graf, P., \& Uttr, B. (1995). Process dissociation procedure: Core assumptions fail, sometimes. European Journal of Cognitive Psychology, 7, 19-40.

KuČera, H., \& Francis, W. N. (1967). Computationalanalysis of present day American English. Providence, RI: Brown University.

Light, L. L., \& ANDERson, P. A. (1983). Memory for scripts in young and older adults. Memory \& Cognition, 11, 435-444.

MANDLER, G. (1980). Recognising: The judgment of a previous occurrence. Psychological Review, 27, 252-271.

Nelson, H. E. (1985). National Adult Reading Test. London: NFERNelson.

Paivio, A., Yuille, J. C., \& Madigan, S. A. (1968). Concreteness, im- agery, and meaningfulness values for 925 nouns. Journal of Experimental Psychology Monograph Supplement, 76, 1-25.

Parkin, A. J., \& WALter, B. M. (1992). Recollective experience, normal aging, and frontal dysfunction. Psychology \& Aging, 7, 290-298.

Parkin, A. J., Ward, J., Bindschaedler, C., Squires, E. J., \& PowELL, G. (1999). False recognition following frontal lobe damage: The role of encoding factors. Cognitive Neuropsychology, 16, 243-265.

RAJARAM, S. (1993). Remembering and knowing: Two means of access to the personal past. Memory \& Cognition, 21, 89-102.

Rajaram, S. (1996). Perceptual effects on remembering: Recollective processes in picture recognition memory. Journal of Experimental Psychology: Learning, Memory, \& Cognition, 22, 365-377.

RAJARAM, S., \& Roediger, H. L., III (1997). Remembering and knowing as states of consciousness during retrieval. In J. D. Cohen \& J. W. Schooler (Eds.), Scientific approaches to consciousness (pp. 213240). Hillsdale, NJ: Erlbaum.

RANKIN, J. L., \& KAUSLER, D. H. (1979). Adult age differences in false recognitions. Journal of Gerontology, 34, 58-65.

Reber, A. S. (1967). Implicit learning of artificial grammars. Journal of Verbal Learning \& Verbal Behavior, 6, 855-863.

Reder, L. M., Wible, C., \& Martin, J. (1986). Differential memory changes with age: Exact retrieval versus plausible inference. Journal of Experimental Psychology: Learning, Memory, \& Cognition, 12, $72-81$

Roediger, H. L., III, \& SRINIVAs, K. (1993). Specificity of operations in perceptual priming. In P. Graf \& M. E. J. Masson (Eds.), Implicit memory: New directions in cognition, development \& neuropsychology (pp. 17-48). Hove, U.K.: Erlbaum.

Russo, R, Cullis, A. M., \& PARKin, A. J. (1998). Consequences of violating the assumption of independence in the process dissociation procedure: A word fragment completion study. Memory \& Cognition, 26, 617-632.

Schacter, D. L., Curran, T., Galluccio, L., Milberg, W. P., \& BATES, J. F. (1996). False recognition and the right frontal lobe: A case study. Neuropsychologia, 34, 793-808.

Schacter, D. L., IsRael, L., \& Racine, C. (1999). Suppressing false recognition in younger and older adults: The distinctiveness heuristic. Journal of Memory \& Language, 40, 1-24.

SNOdgrass, J. G., \& CoRwIN, J. (1988). Pragmatics of measuring recognition memory: Applications to dementia and amnesia. Journal of Experimental Psychology: General, 117, 34-50.

Stanislaw, H., \& Todorov, N. (1999). Calculation of signal detection theory measures. Behavior Research Methods, Instruments, \& Computers, 31, 137-149.

Tulving, E. (1985). Memory and consciousness. Canadian Psychologist, 26, 1-12.

Tulving, E., \& Schacter, D. L. (1990). Priming and human memory systems. Science, 247, 301-306.

Wagner, A. D., Gabrieli, J. D. E., \& Verfaellie, M. (1997). Dissociations between familiarity processes in explicit recognition and implicit perceptual memory. Journal of Experimental Psychology: Learning, Memory, \& Cognition, 23, 305-323.

White, N., \& Cunningham, W. R. (1982). What is the evidence for retrieval problems in the elderly? Experimental Aging Research, 8, 169-171.

Yonelinas, A. P., Regehr, G., \& JACoby, L. L. (1995). Incorporating response bias in a dual-process theory of memory. Journal of Memory \& Language, 34, 821-835.

\section{NOTES}

1. It is not possible to calculate these measures in those instances in which the hit rate is $100 \%$ and/or the false alarm rate is $0 \%$. Therefore, the hit and false alarm rates were transformed using the formulae: (hits -0.5$)$ / $(N+1)$ and (false alarms +0.5$) /(N+1)$, where $N$ is the number of targets or distractors (see Snodgrass \& Corwin, 1988).

2. A similar interpretation has recently been reported in frontal lobe patients who produce a pathological level of false alarms (Parkin, Ward, Bindschaedler, Squires, \& Powell, 1999; Schacter, Curran, Galluccio, Milberg, \& Bates, 1996). 
APPENDIX

Materials Used for Set A in Experiment 1

\begin{tabular}{|c|c|c|c|c|c|c|c|}
\hline \multicolumn{2}{|c|}{$\begin{array}{l}\text { Overlap } \\
\text { (List 1) }\end{array}$} & \multicolumn{2}{|c|}{$\begin{array}{l}\text { Overlap } \\
\text { (List 2) }\end{array}$} & \multicolumn{2}{|c|}{$\begin{array}{c}\text { Nonoverlap } \\
\text { (List 1) }\end{array}$} & \multicolumn{2}{|c|}{$\begin{array}{c}\text { Nonoverlap } \\
\text { (List 2) }\end{array}$} \\
\hline nip & $\mathrm{D}$ & ornate & $\mathrm{D}$ & mucus & $\mathrm{D}$ & pomp & $\mathrm{D}$ \\
\hline cat & $\mathrm{D}$ & swan & D & soup & $\mathrm{D}$ & kiosk & $\mathrm{D}$ \\
\hline head & $\mathrm{D}$ & verbal & D & fop & $\mathrm{D}$ & suspicious & $\mathrm{D}$ \\
\hline hall & $\mathrm{D}$ & marry & $\mathrm{D}$ & fish & $\mathrm{D}$ & pick & $\mathrm{D}$ \\
\hline sweaty & $\mathrm{D}$ & pen & D & music & $\mathrm{D}$ & push & $\mathrm{D}$ \\
\hline indent & $\mathrm{D}$ & indeed & D & skimp & D & cusp & D \\
\hline inlay & $\mathrm{D}$ & sand & $\mathrm{D}$ & couch & $\mathrm{D}$ & posh & $\mathrm{D}$ \\
\hline serenade & $\mathrm{D}$ & style & D & fox & D & chip & $\mathrm{D}$ \\
\hline straddle & $\mathrm{D}$ & touch & $\mathrm{D}$ & spook & $\mathrm{D}$ & shook & $\mathrm{D}$ \\
\hline play & D & slab & D & hiss & $\mathrm{D}$ & skip & $\mathrm{D}$ \\
\hline rump & D & herald & D & suffix & $\mathrm{D}$ & possum & $\mathrm{D}$ \\
\hline pew & $\mathrm{D}$ & saga & $\mathrm{D}$ & opium & $\mathrm{D}$ & kiss & $\mathrm{D}$ \\
\hline slay & D & owe & D & chick & D & hip & D \\
\hline thump & $\mathrm{D}$ & pellet & D & scoop & $\mathrm{D}$ & puff & $\mathrm{D}$ \\
\hline zoo & D & meter & D & scuff & $\mathrm{D}$ & copious & $\mathrm{D}$ \\
\hline zoom & $\mathrm{D}$ & cabaret & $\mathrm{D}$ & coop & $\mathrm{D}$ & muck & $\mathrm{D}$ \\
\hline feeble & D & only & D & cuckoo & $\mathrm{D}$ & pouch & $\mathrm{D}$ \\
\hline celebrate & $\mathrm{D}$ & parent & D & such & $\mathrm{D}$ & suck & $\mathrm{D}$ \\
\hline set & $\mathrm{D}$ & crab & D & cosmos & $\mathrm{D}$ & kick & $\mathrm{D}$ \\
\hline herd & D & stew & D & miss & D & vicious & D \\
\hline topic & $\mathrm{D}$ & feel & $\mathrm{D}$ & sip & $\mathrm{D}$ & fuss & $\mathrm{D}$ \\
\hline magnet & D & keel & D & shop & $\mathrm{D}$ & hush & $\mathrm{D}$ \\
\hline cranberry & $\mathrm{D}$ & stagnate & $\mathrm{D}$ & hump & $\mathrm{D}$ & sock & $\mathrm{D}$ \\
\hline heyday & $\mathrm{D}$ & strewn & D & cosmic & $\mathrm{D}$ & hoop & $\mathrm{D}$ \\
\hline cedar & D & roof & D & musk & $\mathrm{D}$ & mimic & D \\
\hline calendar & $\mathrm{T}$ & farewell & $\mathrm{T}$ & jab & $\mathrm{T}$ & warren & $\mathrm{T}$ \\
\hline merge & $\mathrm{T}$ & settle & $\mathrm{T}$ & great & $\mathrm{T}$ & newt & $\mathrm{T}$ \\
\hline tuck & $\mathrm{T}$ & ask & $\mathrm{T}$ & wane & $\mathrm{T}$ & beat & $\mathrm{T}$ \\
\hline veranda & $\mathrm{T}$ & verb & $\mathrm{T}$ & garb & $\mathrm{T}$ & blend & $\mathrm{T}$ \\
\hline herb & $\mathrm{T}$ & standby & $\mathrm{T}$ & tread & $\mathrm{T}$ & way & $\mathrm{T}$ \\
\hline sweet & $\mathrm{T}$ & sewerage & $\mathrm{T}$ & gent & $\mathrm{T}$ & beret & $\mathrm{T}$ \\
\hline wisp & $\mathrm{T}$ & urn & $\mathrm{T}$ & yarn & $\mathrm{T}$ & talent & $\mathrm{T}$ \\
\hline peel & $\mathrm{T}$ & toxic & $\mathrm{T}$ & dredge & $\mathrm{T}$ & jean & $\mathrm{T}$ \\
\hline box & $\mathrm{T}$ & saw & $\mathrm{T}$ & lewd & $\mathrm{T}$ & bleat & $\mathrm{T}$ \\
\hline vandal & $\mathrm{T}$ & lump & $\mathrm{T}$ & tartar & $\mathrm{T}$ & gargle & $\mathrm{T}$ \\
\hline pedal & $\mathrm{T}$ & sable & $\mathrm{T}$ & weld & $\mathrm{T}$ & bean & $\mathrm{T}$ \\
\hline pale & $\mathrm{T}$ & plant & $\mathrm{T}$ & lab & $\mathrm{T}$ & energy & $\mathrm{T}$ \\
\hline valley & $\mathrm{T}$ & meander & $\mathrm{T}$ & tree & $\mathrm{T}$ & byway & $\mathrm{T}$ \\
\hline mandate & $\mathrm{T}$ & urban & $\mathrm{T}$ & table & $\mathrm{T}$ & lean & $\mathrm{T}$ \\
\hline urgent & $\mathrm{T}$ & fragrant & $\mathrm{T}$ & natty & $\mathrm{T}$ & delta & $\mathrm{T}$ \\
\hline create & $\mathrm{T}$ & peal & $\mathrm{T}$ & bangle & $\mathrm{T}$ & degree & $\mathrm{T}$ \\
\hline straw & $\mathrm{T}$ & idle & $\mathrm{T}$ & need & $\mathrm{T}$ & bread & $\mathrm{T}$ \\
\hline hazard & $\mathrm{T}$ & palette & $\mathrm{T}$ & rag & $\mathrm{T}$ & breezy & $\mathrm{T}$ \\
\hline lip & $\mathrm{T}$ & fare & $\mathrm{T}$ & wall & $\mathrm{T}$ & angel & $\mathrm{T}$ \\
\hline duck & $\mathrm{T}$ & epic & $\mathrm{T}$ & barn & $\mathrm{T}$ & waltz & $\mathrm{T}$ \\
\hline $\operatorname{dim}$ & $\mathrm{T}$ & bush & $\mathrm{T}$ & water & $\mathrm{T}$ & rattle & $\mathrm{T}$ \\
\hline otter & $\mathrm{T}$ & say & $\mathrm{T}$ & greedy & $\mathrm{T}$ & legendary & $\mathrm{T}$ \\
\hline mend & $\mathrm{T}$ & haze & $\mathrm{T}$ & dangle & $\mathrm{T}$ & bet & $\mathrm{T}$ \\
\hline steward & $\mathrm{T}$ & ferry & $\mathrm{T}$ & warrant & $\mathrm{T}$ & add & $\mathrm{T}$ \\
\hline hare & $\mathrm{T}$ & boom & $\mathrm{T}$ & eat & $\mathrm{T}$ & agree & $\mathrm{T}$ \\
\hline
\end{tabular}

Note-Set B was identical, but with the target (T) and distractor (D) status reversed.

(Manuscript received January 5, 1999;

revision accepted for publication January 9, 2001.) 